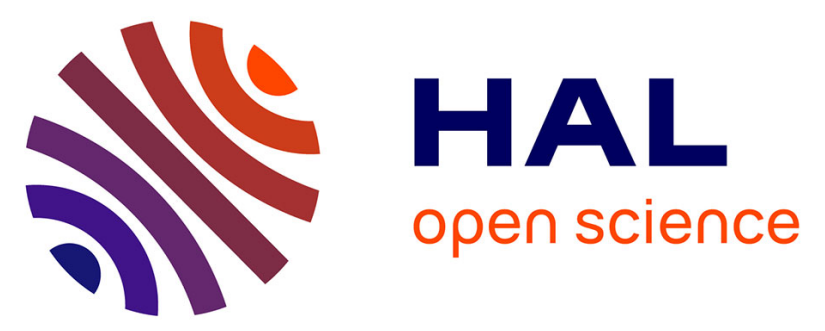

\title{
Tuning the load in gold and magnetic nanoparticles in nanogels through their design for enhanced dual magneto-photo-thermia
}

Esther Cazares-Cortes, Claire Wilhelm, Jose Efrain Perez, Ana Espinosa, Sandra Casale, Aude Michel, Ali Abou-Hassan, Christine Ménager

\section{To cite this version:}

Esther Cazares-Cortes, Claire Wilhelm, Jose Efrain Perez, Ana Espinosa, Sandra Casale, et al.. Tuning the load in gold and magnetic nanoparticles in nanogels through their design for enhanced dual magneto-photo-thermia. Chemical Communications, In press, 10.1039/D0CC07176E . hal-03236485

\section{HAL Id: hal-03236485 \\ https://hal.sorbonne-universite.fr/hal-03236485}

Submitted on 26 May 2021

HAL is a multi-disciplinary open access archive for the deposit and dissemination of scientific research documents, whether they are published or not. The documents may come from teaching and research institutions in France or abroad, or from public or private research centers.
L'archive ouverte pluridisciplinaire HAL, est destinée au dépôt et à la diffusion de documents scientifiques de niveau recherche, publiés ou non, émanant des établissements d'enseignement et de recherche français ou étrangers, des laboratoires publics ou privés. 


\section{Tuning the load in gold and magnetic nanoparticles in nanogels through their design for enhanced dual magneto-photo-thermia}

Received 00th January 20xx, Accepted 00th January 20xx
Esther Cazares-Cortes ${ }^{a}$, Claire Wilhelm ${ }^{b}$, Jose Efrain Perez ${ }^{b}$, Ana Espinosa ${ }^{b, c}$, Sandra Casale ${ }^{d}$, Aude Michel $^{a}$, Ali Abou-Hassan*a and Christine Ménager*a

DOI: $10.1039 / \times 0 \times x 00000 x$

We describe a novel synthesis allowing to enhance the load in magnetic nanoparticles and gold nanorods in nanogels. Two different structures, simple cores and core-shells were synthesized and their heating properties upon alternating magnetic field or laser exposure are compared. Remarkably, the core-shell structure showed a greater heating capacity in the two modalities.

Hybrid nanogels containing nanoparticles could be one of the next-generation therapeutics in nanomedicine addressing the need for efficient remote onsite treatments minimizing side effects. Indeed, nanogels combine the intrinsic properties of a polymer network which can be $\mathrm{pH}$, temperature or redox sensitive with functional nanoparticles embedded in the matrix. ${ }^{1}$ The gel part was mostly developed for drug delivery applications with the possibility to control in space and time the drug release with an intracellular stimulus ( $\mathrm{pH}$, redox activation) and/or an external one (magnetic field, light, ultrasound). Among the nanoparticles that can be used for remote control, magnetic nanoparticles (MNP) and gold nanoparticles (AuNP) are particularly promising because they can deliver heat locally after alternating magnetic field stimulation or laser irradiation, respectively..$^{2-8}$ It then becomes logical to think about triggering a phase transition of the polymer network, which needs then to be thermoresponsive, by the nanoparticles-generated heat. Initially, such hybrid thermosensitive nanogels were achieved using the PNIPAM (poly-N-isopropylacrylamide) polymer, which may suffer from toxicity issues. Then, a new generation of biocompatible and thermosensitive polymers based on oligo(ethylene glycol) methyl ether methacrylate derivates (OEGMA) was developed. ${ }^{9-11}$ Herein, the goal was to develop OEGMA-based hybrid nanogels and to endow it with both magnetic and plasmonic functions for ultra-efficient heating.

\footnotetext{
a. Sorbonne Université, CNRS UMR 8234, Physico-chimie des Électrolytes et Nanosystèmes InterfaciauX, F-75005 Paris, France, Email: ali.abou hassan@sorbonne-universite.fr; christine.menager@sorbonneuniversite.fr

b. Université de Paris, CNRS, UMR 7057, Laboratory MSC, 75205 Paris cedex 13, France

. IMDEA Nanociencia, c/ Faraday, 9, 28049 Madrid, Spain and Nanobiotecnología (IMDEA-Nanociencia), Unidad Asociada al Centro Nacional de Biotecnología (CSIC), 28049 Madrid, Spain

d. Sorbonne Université, CNRS UMR 7197, Laboratoire de Réactivité de Surface, 4

Place Jussieu, F75005Paris, France

† Footnotes relating to the title and/or authors should appear here.

Electronic Supplementary Information (ESI) available: [Materials and methods, synthesis of magnetic and gold nanoparticles, nanogels syntheis, characterizations (FTIR, DLS, UV-Vis-NIR) and thermal characterizations ]. See DOI: $10.1039 / \mathrm{x} 0 \mathrm{xx} 00000 \mathrm{x}$
}

Recent works proposed the engineering of hybrid magnetic and plasmonic inorganic nanoparticles as theranostic nanoplatforms. Mainly the magnetic (generally iron oxide based) part is used to provide contrast for magnetic resonance imaging (MRI) and to achieve magnetic guidance and targeting, while the gold part was mostly exploited for its optical properties allowing photothermal imaging and heating. ${ }^{12-16}$ Synergies resulted from the combination of these two materials, such as iron oxide nanoflowers with a gold shell ${ }^{17}$ and iron oxide nanoparticles coated with a $\mathrm{Fe}_{3} \mathrm{O}_{4} @$ Au gold layer. ${ }^{18}$ To the best of our knowledge, effective magneto-plasmonic hybrid nanogels for bimodal thermotherapy (magnetic hyperthermia and photothermia) and the controlled drug release remain rare. ${ }^{19,20}$

In this work, we propose an unprecedented synthesis of a magneto-plasmonic core-shell nanogel made of a biocompatible and temperature responsive OEGMA polymer. Importantly, the core-shell design was compared with a simple core nanogel where both magnetic and plasmonic nanoparticles are co-encapsulated within the gel. The choice of the inorganic parts, i.e. the magnetic and gold nanoparticles, was dictated by two criteria: their biocompatibility and their physical properties. Ferric oxide (maghemite $\gamma-\mathrm{Fe}_{2} \mathrm{O}_{3}$ ) was chosen for magnetic nanoparticles (MNPs) because of their well-controlled magnetic hyperthermia properties and gold nanorods (AuNRs) were selected for their plasmon resonance band localized in the near infra-red region.

For the synthesis of the magneto-plasmonic nanogel assemblies (PlasmMagNanoGels) positively charged MNPs ${ }^{21,22}$ of a diameter $\sim 11.5 \mathrm{~nm}$ and zeta potential of $+25 \mathrm{mV}$ (see ESI and Figure S1) and CTAB (cetyltrimethylammonium Bromide) coated AuNRs (length $\sim 40 \mathrm{~nm}$; width $\sim 12 \mathrm{~nm}, \lambda=753 \mathrm{~nm})^{23}$ and zeta potential at $+45 \mathrm{mV}$ (see ESI and Figure S2) were used as building blocks. Two approaches were envisaged for tuning the load in AuNRs and MNPs in the nanogels, with the synthesis steps described in Figure 1 . The interplay between chemical functionalities, the swelling states of the gels and the order of addition of the NPs allowed the preparation of two different morphologies: Nanogels loaded with MNPs and AuNRs (MNPs+AuNRs; Figure 1A) and nanogels with a magnetic core 
containing MNPs with AuNRs in the shell of the nanogel (MNPs@AuNRs, Figure 1B).
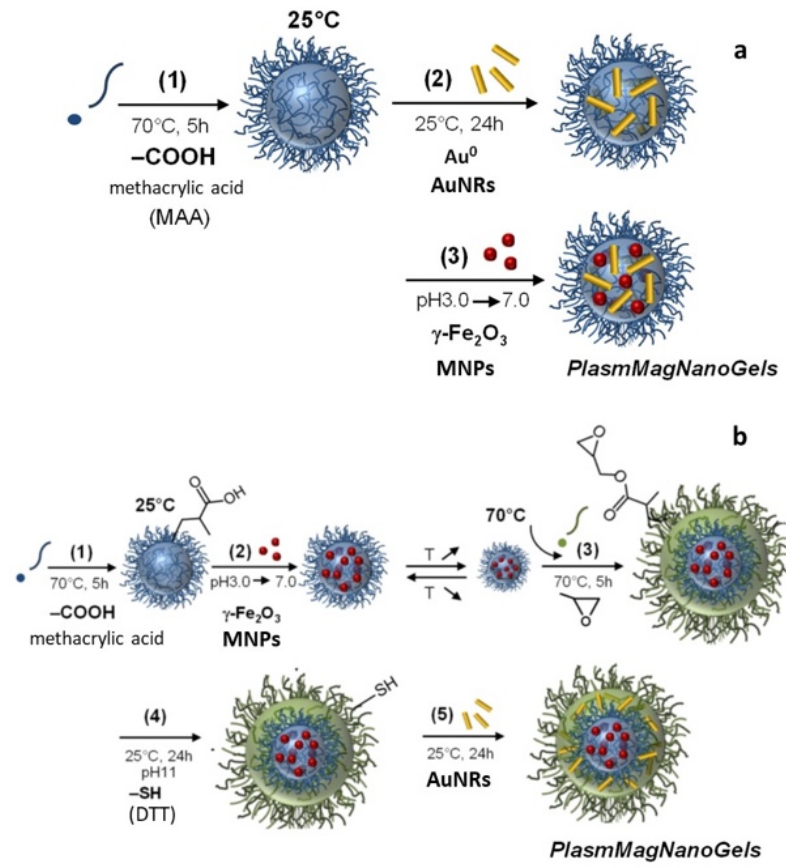

Figure 1. Illustration of PlasmMagNanoGels synthesis: (a) simple core structure co-encapsulating magnetic and plasmonic nanoparticles (MNPs+AuNRs); (b) core-shell structure with magnetic nanoparticles in the core and plasmonic nanoparticles in the shell (MNPs@AuNR). DTT: 1,4dithiothreitol.

The first step for all the assemblies is the synthesis of the OEGMA based nanogels functionalized with carboxylic acid groups (OEGMA-COOH) by incorporation of methacrylic acid during the reticulation step. The nanogels were obtained using the conventional precipitation radical copolymerization in water as described in ESI. ${ }^{24}$ To assemble the co-encapsulating PlasmMagNanoGels (MNPs+AuNRs), the second step (Figure 1a, step 2) consisted in swelling of the nanogels at $25^{\circ} \mathrm{C}$ to allow first the passive diffusion of the positively charged AuNRs in their core and electrostatic attraction to the carboxylate groups of the methacrylic acid. To achieve high Au loading different $\mathrm{Au}$ mass ratio of AuNRs initially added was varied in the mixture (see ESI). The third and final step (Figure 1a, step 3) consisted in encapsulating the MNPs, ${ }^{24}$ after swelling the nanogels at $25^{\circ} \mathrm{C}$ by complexation and binding of the carboxylate groups of the OEGMA matrix to iron atoms on MNPs surface. To ensure a good complexation of the MNPs the initial $\mathrm{pH}$ of the nanogels was adjusted from 3 to 7 . The amount of AuNRs was fixed to $3.1 \%$ (mass ratio) but different preparations were tested by adding a variable amount of MNPs. We observed that when the amount of MNPs added increased, the amount of AuNRs incorporated in the nanogels decreased in turn. This phenomenon is visible on the transmission electron microscopy (TEM) images presented on Figure $2 \mathrm{~b}-\mathrm{d}$ of nanogels containing an $\mathrm{Au}$ initial mass ratio constant (3.1\%) and an increasing $\mathrm{Fe}$ initial mass ratio of $X=4.4 \%, 15.5 \%$ and $26.9 \%$ for images $b, c$, and $d$, respectively. This observation was also confirmed by ICP-
$A E S$, the final mass ratio of $A u$ is $0.79 \%, 0.31 \%$ and $0.15 \%$ for $X=$ $4.4 \%, 15.5 \%$ and $26.9 \%$ respectively. The driving force behind the encapsulation of AuNRs and MNPs in the nanogels is diffusion. Consequently, the diminution of encapsulation of AuNRs within the nanogels can be attributed to the fast diffusion of MNPs driven by a stronger concentration gradient from the outside to the core of the gel in addition to their smaller size in comparison with AuNRs. The most efficient structure corresponding to a loading with AuNRs at $[\mathrm{Au}]=$ 5.4.10-4 mol. $\mathrm{L}^{-1}$ and with MNPs at $[\mathrm{Fe}]=1.14 \mathrm{~mol} . \mathrm{L}^{-1}$ (Figure $2 \mathrm{~d}$ ) was additionally observed by energy dispersive energydispersive $\mathrm{X}$-ray spectroscopy analysis (EDX-STEM) as shown in Figure 2e (Au cartography), Figure $2 \mathrm{~g}$ (Fe cartography) and Figure $2 \mathrm{~g}$ (merged). All confirmed the presence of both type of NPs with MNPs and AuNRs extending in the entire gel. Finally, at $25^{\circ} \mathrm{C}$ and $\mathrm{pH} 5.5$, the hydrodynamic diameter ( $\mathrm{dh}$ ) of MNP+AuNRs nanogels increased from 423 to $515 \mathrm{~nm}$ when the added amount of MNPs increased from $4.4 \%$ to $26.9 \%$. Motivated by increasing the load in AuNPs and MNPs in the nanogel structure we used a second strategy which consist in attaching AuNPs around the magnetic core gel. To produce the MNPs@AuNRs core@shell organization (Figure 1b), OEGMA$\mathrm{COOH}$ nanogels loaded with MNPs at $25^{\circ} \mathrm{C}$ and as described previously were prepared (steps $1 \& 2$ ). Next thiol (SH) anchoring groups were created for the attachment of the AuNRs on the surface of the nanogels using a thiol-epoxy click chemistry reaction. To do that, first a polymer shell incorporating glycidyl methacrylate (GMA, Figure 1b, step 3) was created around the magnetic cores. Upon heating at $70^{\circ} \mathrm{C}$ the magnetic gels shrunk and the OEGMA-epoxy shell (Figure 1 b, step 3) grew by radical copolymerization around the cores. In this step, the cores serve as nucleation sites to start the shell copolymerization process. The final step of the functionalization (Figure 1b, step 4) was achieved by reacting 1,4-dithiothreitol (DTT) with the epoxy groups generating $\mathrm{SH}$ groups. ${ }^{25}$ The assembly of the AuNRs around the magnetic cores was achieved by forming covalent bonds between the thiol groups (-SH) and the surface of the AuNRs at $25^{\circ} \mathrm{C}$ (Figure $1 \mathrm{~b}$, step 5).

Images obtained for the core shell structures (MNPs@AuNRs, Figure 2h) are shown in Figure 2i-l, using TEM (Figure $2 \mathrm{i}$ ) and EDX-STEM (Figure $2 \mathrm{j}$ and $2 \mathrm{k}$ for $\mathrm{Au}$ and $\mathrm{Fe}$ cartography respectively and Figure $2 \mathrm{l}$ for $\mathrm{Au}+\mathrm{Fe}$ ). Finally, the addition of a surfactant (sodium dodecyl sulfate, SDS) during core synthesis allowed to control later on the overall size of the prepared core-shell. For SDS $=0,1.7,4.4,8.8$ and $19.1 \mathrm{mg}$, the dh of the core was 475, 350, 319, 261 and $252 \mathrm{~nm}$, respectively (see ESI, Figure S3). For both nanogels, the loading of $\mathrm{Au}$ and MNPs is efficient and the spatial distribution appears significantly different for the two structures. For MNPs@AuNRs, the amount of loaded AuNRs is more important and the AuNRs appear localized mostly in the shell where only few MNPs coexist. This observation was verified by the titration of Fe and $\mathrm{Au}$. The final Au concentration was $0.05 \mathrm{mM}$ in the simple core structure whereas it reached $2.2 \mathrm{mM}$ in the core@shell structure. The concentration of MNPs was also higher in the core@shell with $[\mathrm{Fe}]=2.7 \mathrm{mM}$ and $4.7 \mathrm{mM}$ for MNPs+AuNRs and MNPs@AuNRs respectively. The higher loading in both 
magnetic and gold NPs was also deduced from UV-Vis-NIR spectroscopy (ESI, figure S4b) and magnetic manipulation of the gels (ESI, Figure S4a), which showed a higher absorption intensity of AuNPs and a faster attraction to the magnet for the core@shell structures. As a conclusion the core@shell synthesis with successive complexation of MNPs and AuNRs leads to a better encapsulation of both NPs.
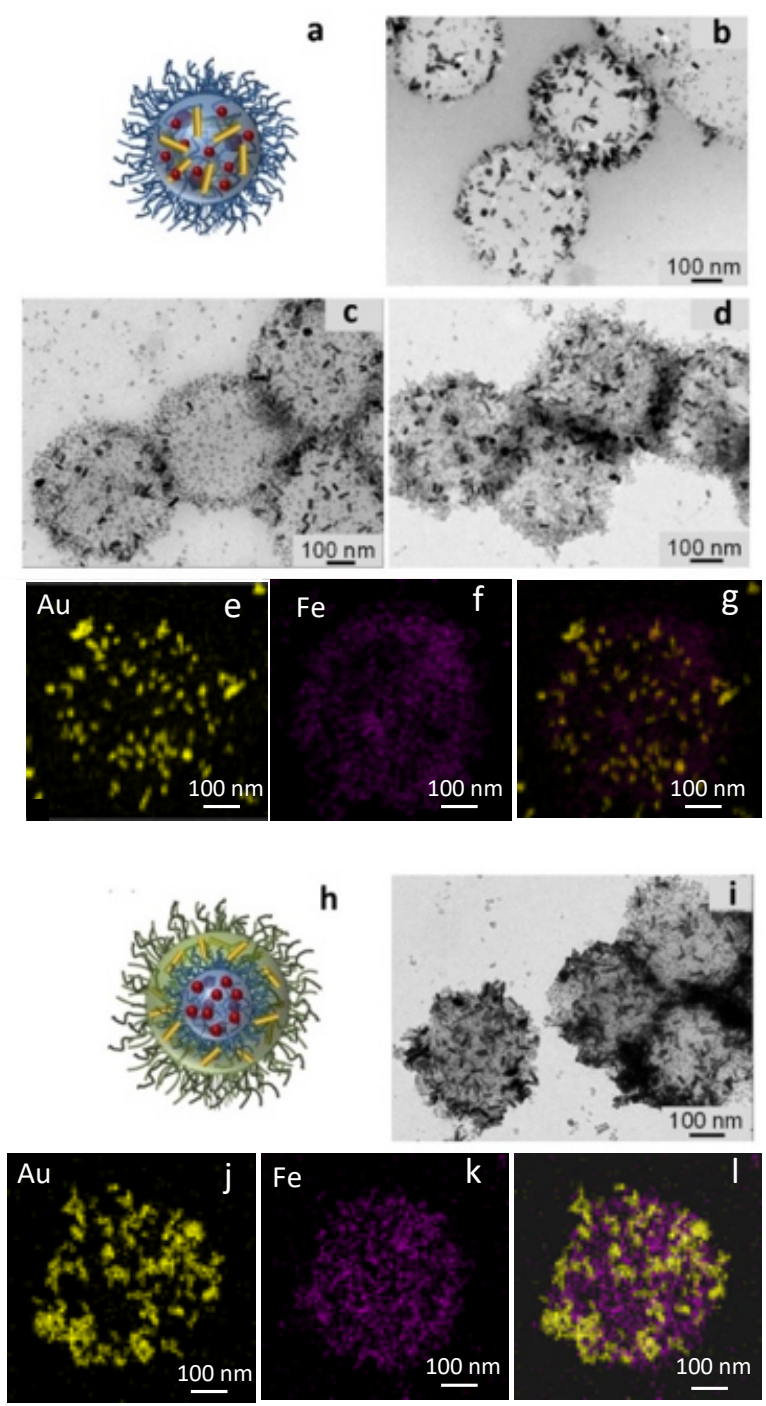

Figure 2. a. MNPs+AuNRs nanogels. b-d. Electron microscopy images of MNPs+AuNRs, with initial mass ratio FeX\%-AuY\%, with MNPs ratio $X=4.4 \%$ (b); $15.5 \%$ (c) and $26.9 \%$ (d) and the same AuNR ratio of $Y=3.1 \%$. e-g. From left to right, EDX-STEM with gold (yellow), iron (purple) and merged, for the composition corresponding to image $d([\mathrm{Au}]=0.05 \mathrm{mM}$ and $[\mathrm{Fe}]=2.7 \mathrm{mM})$. $\mathrm{h}$. MNPs@AuNRs nanogels ([Au] $=2.2 \mathrm{mM}$, [Fe]=4.7 mM. i. TEM image. j-I. EDXSTEM with gold (yellow, iron (purple) and merged. Note that for the TEM images, the nanogels appear to be in contact with other but this is only due to their drying on the grids. By contrast, the hydrodynamic diameter measurements are consistent with stable aqueous dispersion of the nanogels.

Both nanogels were then evaluated as nano-heaters. The dual encapsulation of AuNRs and MNPs was envisaged to allow the application of two heating modalities: magnetic hyperthermia (MHT, with respect to the MNPs), and photothermia (PTT, with respect to the AuNRs). Figure 3 shows the thermal images of the two batches of PlasmMagNanoGels dispersions, simple MNPs+AuNRs (Figure 3a) and core@shell MNPs@AuNRs (Figure $3 b)$, upon alternating magnetic field (AMF) stimulation, or laser exposure at $808 \mathrm{~nm}$ (near infra-red, NIR), or both (AMF+NIR) for 5 min. Typical heating curves are shown in ESI Figure S5. The nanogels were diluted in water at different concentrations, ranging from $[\mathrm{Au}]=0.04$ to $16 \mathrm{mM}$ and $[\mathrm{Fe}]=6$ to $40 \mathrm{mM}$. Only the two highest concentrations are shown in Figure 3, because they were the only ones to heat by MHT. MHT heating was nevertheless only an increase by a few degrees, whereas PTT could produce a high temperature increase for both nanogels of $10^{\circ} \mathrm{C}$ and more. Remarkably, when applying $\mathrm{MHT}$ and $\mathrm{PTT}$ simultaneously, an additive effect of the temperature increase is observed ( $\mathrm{T} \approx 11$ to $24^{\circ} \mathrm{C}$ ), leading to a dual magneto-photothermal modality.
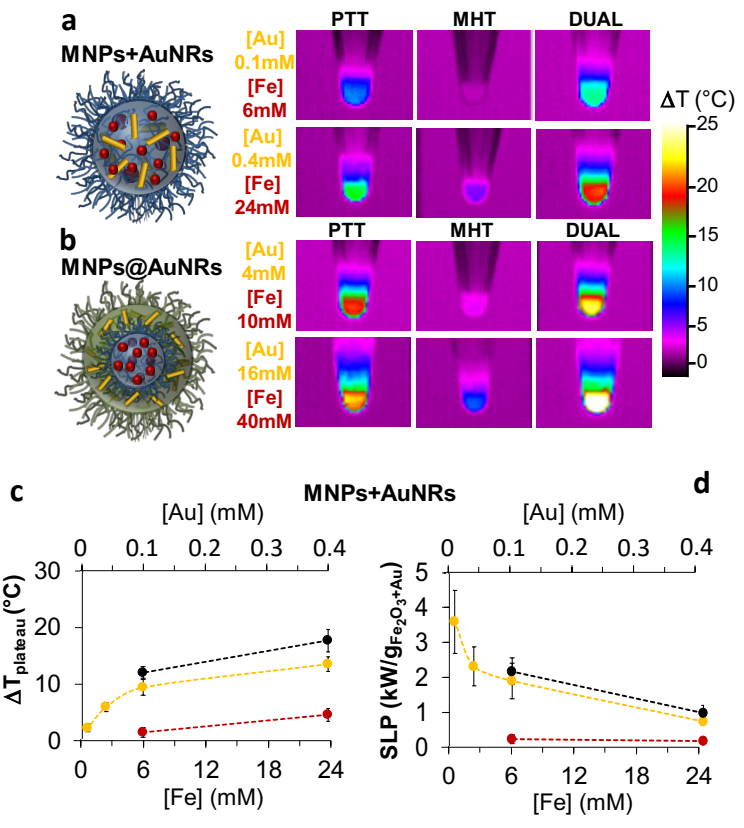

d

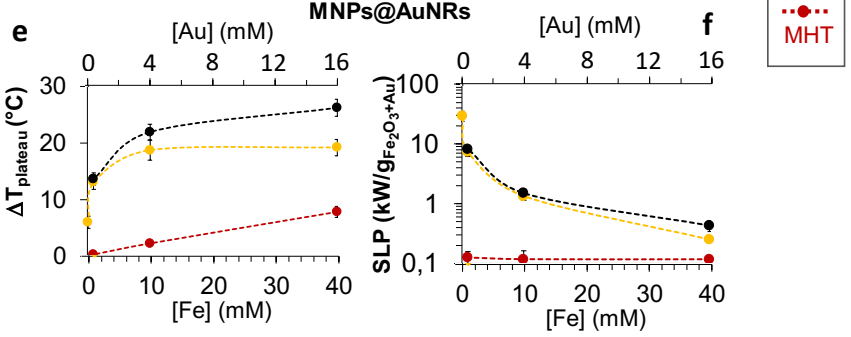

Figure 3. Panel of thermal images of (a) MNPs+AuNRs and (b) MNPs@AuNRs dispersions $(50 \mu \mathrm{L})$ acquired by an IR camera on samples at different iron and gold concentration, as specified in the figure, and after $5 \mathrm{~min}$ exposure to an alternating magnetic field (MHT) or laser (PTT) or both (DUAL). MHT was performed at $470 \mathrm{kHz}$ and 18 $\mathrm{mT}$; PTT was performed at $808 \mathrm{~nm}$ wavelength, for a laser power density of $0.3 \mathrm{~W} / \mathrm{cm}^{2}$. Temperature increase upon PTT, MHT, or both (DUAL) is shown for MNPs+AuNRs (c) and MNPs@AuNRs (e) as a function of the solution concentration. SLP (specific loss power) used as a quantification of the heating power of the materials, and expressed in Watts per total grams of inorganic material $\left(\gamma-\mathrm{Fe}_{2} \mathrm{O}_{3}+\mathrm{Au}\right)$, is shown for MNPs+AuNRs (d) and MNPs@AuNRs (f). 
The heat produced by the nanogels depends strongly on the concentration of iron and gold within the nanogels dispersion. The averages of temperature increase are shown in Figure 3c (MNPs+AuNRs) and Figure 3e (MNPs@AuNRs), for the whole range of nanogels concentration in the dispersions. Here the concentration is the global concentration in the nanogels dispersion. Because the loading is more efficient for the core@shell structure, the final concentration of the MNPs@AuNRs is much more important than for the MNPs+AuNRs. As a result, the MNPs@AuNRs heat much more than the MNPs+AuNRs structure.

For PTT, the maximal temperature elevation reached for MNPs+AuNRs is in the $10^{\circ} \mathrm{C}$ range (Figure $3 \mathrm{C}$ ), while it is $20^{\circ} \mathrm{C}$ for MNPs@AuNRs (Figure 3e). The dual magneto-photo-thermal modality then works only for the MNPs@AuNRs nanogels, reaching the highest temperature increase of about $30^{\circ} \mathrm{C}$ (Figure 3e). Usually, one parameter to quantify the heating by renormalization with concentration is the SLP (in W per gram). It should be expressed here in Watt per gram of material, thus maghemite $\left(\mathrm{Fe}_{2} \mathrm{O}_{3}\right)$ and $\mathrm{Au}$. The SLP for MHT is then dramatically lower (in the $100 \mathrm{~W} / \mathrm{g}$ range) for both structures (Figures $3 \mathrm{~d}$ and $3 \mathrm{f}$ ), than for the PTT (in the $2000 \mathrm{~W} / \mathrm{g}$ range). Because $\mathrm{PTT}$ saturates at high concentration, while MHT does not, the SLP for PTT decreases with concentration, while SLP of MHT is constant. Interestingly, if both structures heating is shown on the same graphs (ESI figure S6a for PTT, figure S6b for MHT), they behave the same with concentration. PTT saturates at high concentration, while MHT does not. The SLP for PTT also adjusts on the same curve (ESI figure S6c, then SLP is expressed per mass of Au only). For MHT (ESI figure S6d), SLP is remarkably constant for both, here expressed per gram of Fe only, and is found to be in the $300 \mathrm{~W} / \mathrm{g}$ Fe range, which is in fact a very important value for the MHT modality. Besides MHT is still very efficient after nanogels encapsulation while it is admitted to be reduced for instance after biological encapsulation, which is thus an asset for future applications.

Overall, we show the successful production of OEGMA polymer-based nanogels, as well as their post-functionalization for efficient complexation with MNPs and AuNRs, with the ability to tune their encapsulation process and thus their distribution in the nanogel, yielding two configurations: coencapsulation of both MNPs and AuNRs in the nanogel, and a core@shell structure with MNPs in the core of the gel and AuNRs in its shell. Both formulations are capable heaters in both the MHT and PTT modalities, with the latter being overall more efficient. Importantly, the core@shell structure shows a higher heating efficiency in both modalities, which translates to a significant increase of heat production for dual magneto-photothermia. The magneto-plasmonic nanogels show promise in therapeutic applications, particularly drug release due to the thermosensible nature of the nanogel.

\section{Conflicts of interest}

There are no conflicts to declare.
M. Karg and T. Hellweg, J. Mat. Chem. , 2009, 19, 87148727.

J.-P. Fortin, C. Wilhelm, J. Servais, C. Ménager, J.-C. Bacri and F. Gazeau, J. Am. Chem. soc., 2007, 129, 2628-2635. S. M. Mirvakili, Q. P. Ngo and R. Langer, Nano Letters, 2020, 20, 4816-4822.

A. Plan Sangnier, R. Aufaure, S. Cheong, L. Motte, B. Palpant, R. D. Tilley, E. Guenin, C. Wilhelm and Y. Lalatonne, Chem. Commun., 2019, 55, 4055-4058.

C.-k. Kim, P. Ghosh and V. M. Rotello, Nanoscale, 2009, 1, 61-67.

N. S. Abadeer and C. J. Murphy, J. Phys. Chem. C., 2016, 120, 4691-4716.

J. Song, J.-B. Pan, W. Zhao, H.-Y. Chen and J.-J. Xu, Chem. Commun., 2020, 56, 6118-6121.

B. Wang, R. Li, G. Guo and Y. Xia, Chem. Commun., 2020, 56, 8996-8999.

M. Karg, A. Pich, T. Hellweg, T. Hoare, L. A. Lyon, J. J. Crassous, D. Suzuki, R. A. Gumerov, S. Schneider, I. I. Potemkin and W. Richtering, Langmuir, 2019, 35, 62316255.

F. Xu, H. Sheardown and T. Hoare, Chem. Commun., 2016, 52, 1451-1454.

F. Lutz, J. Polym. Sci. A: Polym. Chem., 2008, 46, 34593470.

A. J. Coughlin, J. S. Ananta, N. Deng, I. V. Larina, P. Decuzzi and J. L. West, Small, 2014, 10, 556-565.

Z. Fan, M. Shelton, A. K. Singh, D. Senapati, S. A. Khan and P. C. Ray, ACS nano, 2012, 6, 1065-1073.

G. A. Sotiriou, F. Starsich, A. Dasargyri, M. C. Wurnig, F. Krumeich, A. Boss, J. C. Leroux and S. E. Pratsinis, Adv. Funct. Mat. , 2014, 24, 2818-2827.

I. Urries, C. Muñoz, L. Gomez, C. Marquina, V. Sebastian, M. Arruebo and J. Santamaria, Nanoscale, 2014, 6, 92309240.

C. H. Wu, J. Cook, S. Emelianov and K. Sokolov, Adv. Funct. Mat. , 2014, 24, 6862-6871.

A. Espinosa, M. Bugnet, G. Radtke, S. Neveu, G. A. Botton, C. Wilhelm and A. Abou-Hassan, Nanoscale, 2015, 7, 18872-18877.

F. Mohammad, G. Balaji, A. Weber, R. M. Uppu and C. S. Kumar, J. Phys. Chem. C., 2010, 114, 19194-19201.

C. Chi, T. Cai and Z. Hu, Langmuir, 2009, 25, 3814-3819.

A. Riedinger, M. Pernia Leal, S. R. Deka, C. George, I. R. Franchini, A. Falqui, R. Cingolani and T. Pellegrino, Nano letters, 2011, 11, 3136-3141.

S. Lefebure, E. Dubois, V. Cabuil, S. Neveu and R. Massart, J. Mat. Res., 1998, 13, 2975-2981.

A. Abou-Hassan, J.-F. Dufrêche, O. Sandre, G. Mériguet, O. Bernard and V. Cabuil, J. Phys. Chem. C., 2009, 113, 18097-18105.

B. Nikoobakht and M. A. El-Sayed, Chem. Mat. , 2003, 15, 1957-1962.

E. Cazares-Cortes, A. Espinosa, J.-M. Guigner, A. Michel, N. Griffete, C. Wilhelm and C. Ménager, ACS App. Mat. Interf. s, 2017, 9, 25775-25788.

M. C. Stuparu and A. Khan, J. Polym. Sci., Part A: Polym Chem. 2016, 54, 3057-3070

\section{Notes and references}

